\title{
Ekolojik Sistem Yaklaşımı Çerçevesinde Bir Olgu Sunumu: Suça Sürüklenen Çocuk Ve Ailesi Üzerine Çalışma
}

\author{
Deniz YILMAZ ${ }^{1 *}$ \\ ${ }^{1}$ Uzman Psikolog, Bartın Aile ve Sosyal Politikalar İl Müdürlüğü
}

Öz

Ekolojik sistem yaklaşımı, bireyi, çevresi içerisinde yaşayan bir varlık olarak ele alır ve bireyin davranışını değerlendirirken bu çevreyi de göz önünde bulundurur ve sorunun çözümüne bu noktadan hareketle başlar. $\mathrm{Bu}$ çalışmada, bir bakkal dükkânından hırsızlık yaptığı gerekçesiyle ilgili mahkemece hakkında Danışmanlık Tedbiri kararı verilen 16 yaşında bir erkek çocuğu ile yapılan mesleki çalışmada Ekolojik Sistem yaklaşımı kullanılmıştır. Buna göre, çocuk, içinde bulunduğu sistem içerisinde değerlendirilmiş ve her bir sistemin değiştirilmesi yoluna gidilerek çocuğun sorunlu davranışlarının düzeltilmesi sağlanmıştır.

Anahtar Kelimeler: Ekolojik Sistem Yaklaşımı, Çocuk Suçluluğu, Soysal Hizmetler

\section{Presentation of Case Study over Juvenile Pushed to Crime and Their Families As Part of Ecological System Approach}

\begin{abstract}
Ecological system approach takes the person as a being who lives together with the environment and takes into consideration this matter while evaluating person's behavior and sorts out the problem starting from this point of view. In this study, Ecological system approach is used for the 16 years old teen who was decided to take advisory support by the reason of stealing from a supermarket. Accordingly, the teen, has been evaluated within the existing social systems and his problematical behaviors are corrected by means of changing these systems.
\end{abstract}

Keyword: Ecological System Theory, Child Delinquency, Social Work 


\section{GíRiș}

Her toplum, kendine özgü, kültür, yapı, bütünlük, sosyal kontrol gibi dinamikleri ile sürekliliğini sağlar. Bu toplumda yaşayan bireyler, yazılı olan veya olmayan ya da günlük hayatın devamlılığını sağlayacak olan pek çok kuralı kabul eder (Sankır, 2014: 1314). Bu toplumsal kurallardan bilinçli ya da bilinçsizce sapıp, konulan kuralların ötesine geçen kişiye sapmış denir (Arıkan, 1986: 2). Sapmış kişi toplumsal kuralı ihlal ettiği için, bu kişinin suç işlediği kabul edilir. Suç, toplumsal kuralı bozma ya da karşı gelme şeklinde tanımlanır. (Yavuzer, 2011: 94). Bir başka değişle, bireyin bağlı olduğu toplumun normlarına "hayır" diyerek karşı çıkması, bu karşı çıkışın derecesine göre, içinde bulunduğu ve baştan bir anlaşma imzalamış olduğu toplumun, dışına atılmasına, suçlanmasına ve cezalandırılmasına yol açar (Köknel, 1987: 398). Yavuzer'in Burt'tan (1937) aktardığına göre ise çocuk suçluluğu, anti-sosyal eğilimlerin yasa müdahalesi gerektirecek bir duruma dönüşmesidir (Yavuzer, 2011: 94). Suçlu çocuk, yaşıtları ve çevresiyle uyumlu ilişkiler kuramayan, vuran, kıran, ısıran, zorbalık yapan çocuktur ve geçimsizdir, kavgaya hazırdır, kuralları çiğner, ceza almaktan kaçınmaz (Kılıçarslan, 2006: 82).

Bu çalışmada toplumdan sapma davranışı gösteren, aslında kanunlarda bir ceza yaptırımına karşılık gelen bir eylemi yapmış olan çocuklara yönelik yapılan mesleki çalışmalarda Ekolojik Sistem Yaklaşımı ele alınacaktır. Ülkemizde, 15.07.2005 tarihinde Çocuk Koruma Kanunu yürürlüğe girmiştir. Bu kanun ile toplumsal kurallardan sapma davranışı gösteren çocuklar suçlu değil, suça sürüklenmiş çocuk olarak kabul edilmiştir. Burada yeni bir slogan vardır: "Suçlu Çocuk Yoktur, Suça Sürüklenmiş Çocuk Vardır”. Yani kanun, çocuğu cezalandırmayı değil de, onu topluma yeniden kazandırmayı amaç edinmiştir. Bu bağlamda, kanunda, çocuk, daha erken yaşta ergin olsa bile, on sekiz yaşını doldurmamış kişiyi; korunma ihtiyacı olan çocuk, bedensel, zihinsel, ahlaki, sosyal ve duygusal gelişimi ile kişisel güvenliği tehlikede olan, ihmal veya istismar edilen ya da suç mağduru çocuğu; suça sürüklenen çocuk, kanunlarda suç olarak tanımlanan bir fiili işlediği iddiası ile hakkında soruşturma veya kovuşturma yapılan ya da işlediği fiilden dolayı hakkında güvenlik tedbirine karar verilen çocuğu belirtmektedir (Çocuk Koruma Kanunu, Md.3, 2005).

Aynı Kanunda, "çocuğun bakımından sorumlu olan kimselere çocuk yetiştirme konusunda; çocuklara da eğitim ve gelişimleri ile ilgili sorunlarının çözümünde yol göstermeye yönelik bir tedbir" olarak tanımlanan danışmanlık tedbirlerinin kapsamı belirtilmiş (ÇKK, Md. 5, 2005), Tebliğ' de ise; Danışmanlık tedbirlerinin kapsamı, çocukların bedensel, zihinsel, psiko-sosyal, duygusal gelişimini desteklemek, okul, aile ve sosyal çevresi ile uyumunu güçlendirmek ve yeteneklerine uygun bir meslek sahibi olarak hayata hazırlanmalarını sağlamak amacıyla okul başarısızlığı, okuma yazma bilmeme, okul devamsızlığı gibi eğitim sorunlarının çözümüne yönelik faaliyetler ve okul başarısını artırma; madde kullanımı, davranış bozukluğu, cinsel istismar, ergenlik sorunları, öfke kontrolü, sosyal beceri sorunu, aile içi iletişim problemleri, ailede parçalanma, ailede çocuğun değeri konusunda yeterli duyarlılığın olmaması, ailenin göçe bağlı sorunları gibi konularda korunma ihtiyacı olan veya suça sürüklenen çocuğu, aileyi ve çocuğun bakımından ve eğitiminden sorumlu kişileri bir arada sistematik bir şekilde ele alan, suç ve mağduriyetin tekrarlanmasını engellemek üzere riskleri ve koruyucu önlemleri değerlendiren ve normal gelişimi destekleyen, müdahale eden, psiko-sosyal ve eğitsel destek hizmetleri olarak uygulanır. (Danışmanlık Tedbir Kararlarının Uygulama Usul ve Esasları Hakkında Tebliğ, Md. 5, 2008).

Çocuğun toplumsal kurallardan sapma davranışı sergilemesi aslında onun etkilenmiş olduğu sistemlerinden kaynaklanmaktadır. Çünkü çocuk suçluluğu çok nedenli bir olgudur. Bu nedenlerin en önemlileri; aile, akran grupları, okul, boş zaman aktiviteleri ve kitle iletişim araçlarıdır (Öter, 2005: 10). Bu bağlamda öncelikle suça sürüklenmiş çocukların ailelerinin incelenmesi şu gerçekleri ortaya çıkarmıştır; Yoksulluk, sorunların başında gelmektedir. Genellikle ailede yoksulluk, aile içi iletişim sorunları, şiddetli geçimsizlik vardır. Bunun yanında ailede ne baba ne de anne tarafından çocukların takibi yapılmamakta, çocuklar bu ailede denetimden uzak büyümektedir. Buna karşın çocuklara karşı uygulanan disiplin genellikle çok serttir. Ceza yöntemi sıklıkla şiddettir. Ya da aile çocuk ile hiç ilgilenmemekte, onu boş bırakmaktadır. Ailedeki bütün bu olumsuzluklara karşın bir de, babanın suça yatkın olduğu ailelerde, çocukların da suça yöneldiği görülmektedir. Ayrılık ve boşanma gibi parçalanmış aile örüntülerinin olması durumunda da çocukların suça yönelme olasılığı artmaktadır (Yörükoğlu, 1978: 297). Bunun yanında aile işlevlerindeki bozulmalar da çocuk suçluluğu üzerinde önemli etkilere sahiptir. Ailenin düşük eğitim düzeyinin, ailedeki kişi sayısı ve olumsuz konut durumunun da çocuk suçluluğu üzerindeki etkileri görülmüştür (Yavuzer, 2006: 127). Ayrıca Uşaklı'nın Uluğ ve Candan'dan (2008) aktardığına göre, Ailede geçimsizliğin yarattığı şiddetli çatışma anne ve baba arasındaki ilişkiyi zayıflatarak boşanmaya neden olmaktadır ve bu boşanmaların sonucu olarak çocuklarda yüksek kaygı, saldırganlık, çekingenlik gibi bir takım anti sosyal 
davranışlar gözlenmektedir (Uşaklı, 2013:196). Buradan şu sonuç çıkmaktadır; Olumsuz aile ortamı ve olumsuz çevre koşulları gibi durumlarla baş edemeyen ergenler olumlu ve kabul edilebilir davranış biçimi geliştirmekte zorluk çekerler ve suça daha kolay sürüklenirler (Gökten 2011: 110). Bunun yanında en fazla rastlanan ruhsal sorunların çocuğun deneyimlerine, yetişmesine ve genel olarak çevresel faktörlere bağlı olduğu da bilinmektedir. (Salk, 1998: 236). Ekolojik sistem yaklaşımının da temelini oluşturan çevre birey ilişkisi, çocuk için de son derece önemlidir. Bu bağlamda çocuğun huy ve ahlakını öncelikle eğitim ve yaşantılar belirlemektedir. Bu da çocuk suçluluğunun kökeninin hukuksal olmaktan öte psikolojik ve sosyolojik olduğunun en temel göstergesidir (Yücel, 1993: 155). Bu noktadan hareket ederek şunu söylemek mümkündür; Çocuk suçluluğunun her aşamasında sosyal hizmetlere gereksinim duyulmaktadır. Çünkü çocukların biyolojik ve psiko-sosyal açıdan sağlıklı gelişimlerine, toplumun değişen koşullarına uyum sağlamalarına yardımcı olmak, onların refahını sağlamak ve sosyal değişmeyi etkilemek, çocukların suça yönelmelerini sağlayan unsurları ortadan kaldırmak ve sosyal işlevselliklerini engelleyen tıkanıklıkları açmak, sosyal bilinci geliştirmek, onların haklarını güvence altına almak, toplumsal refah ve kaynakların dağılımını dengelemek sosyal hizmetlerin temel amacıdır (Danış ve Şahbikan, 2014: 637).

\section{LITERATÜR}

Danış'ın O’Melia, Miley ve DuBois’ten (1998) aktardığına göre Ekolojik Sistem Yaklaşımı, insan davranışına etki eden, iç ve dış kuvvetlerin karşılıklı etkileşimleri üzerinde durur, bireylerin farklı durumlara uyumlarını sağlayan geçerli davranış kalıplarını tanımlar ve çevre içerisinde bulunan insan ve diğer sistemlerin birbirleri üzerinde meydana getirdikleri etkileri açıklar (Akt: Danış, 2006: 46). Buna göre Ekolojik Sistem kavramı, sistemi oluşturan biyofiziksel, beşeri, kurumsal vb. bileşenler arasındaki karşılıklı ilişkinin yarattığı karmaşıklığa dayandırılmaktadır (Berkes vd akt: Kozaman ve Şengezer, 2013). İlişkinin özne olduğu bu yaklaşıma göre, çevrelerindeki unsurlarla sürekli olarak etkileşim içerisinde olan insanlar bu etkileşim yoluyla değişmekte ve gelişmektedirler (Doğan, 2010: 154). Bu değişim ve gelişim sistemin, kısımlarının yapı itibariyle birbirine bağlı ve parçalarının birisi üzerinde meydana gelen değişikliğin diğer parçalarının üzerinde de etki yaptığı, birbiriyle etki-tepki ilişkisi içinde bulunan unsurlardan oluşmuş bir toplum olduğunu gösterir. Bu yaklaşımda toplum, birbirleri ile ilişkili bu unsurların oluşturduğu bir sistem olarak açıklanır. Sisteme ait parçalar sistem bütünlügünden ayrı tutularak anlaşılamazlar, bir başka deyişle hiçbir parça bütünden ayrı değildir (Çelik, 2007: 53). Bu nedenle Ekolojik Sistem Yaklaşımı, sorunun açıklanmasında bireyin içinde bulunduğu çevredeki tüm değişkenlerin hesaba katılmasını öngörür. Bu da bütüncül bakış ve bileşenler arasındaki ilişkileri anlamayla gerçekleşir. Buradaki bütüncüllük kavramıyla, sistem içindeki bütün nesnelerin ve öğelerin bütüncül katkısının, her nesnenin ve her öğenin ayrı ayrı katkısından daha fazla olduğu anlaşılır (Duyan, 2013: 3).

Her öğe ve her nesne derken burada bireyin içinde bulunduğu sistemlerden söz ediyoruz. Sosyal ağ içerisindeki bu sistemler; ev, aile, kültür, alt kültür, toplum, okul gibi sistemlerdir (Danış, 2006: 46). Buna göre, mikrosistem, çocuğun günlük hayatta karşılıklı etkileşim içerisinde olduğu kişileri ve bu kişilerle olan ilişskilerini içerir. Bireyin gelişimi üzerinde en büyük etkiye sahip olan bu sistem, en temelde aileyi, okulu ve arkadaş gruplarını kapsamaktadır (Doğan, 2010: 154). Mezosistem ise, yaşamın belirli bir noktasında, gelişmekte olan bireyi içeren başlıca ortamlar arasındaki etkileşimdir. Çocuğun aktif rol oynamadığı ancak onun yaşantısını ve gelişimini etkileyen kitle iletişim araçları, komşular, sosyal hizmet kurumları ve bütün bu sistemlerin kendi içindeki bağlantılarını sağlayan 'mezosistem'; çocuğun gelişimini dolaylı bir şekilde etkileyen 'ekzosistem'; inanç, değer ve ideolojileri içeren 'makrosistem' içerisinde çocukların gelişimi olumlu ya da olumsuz yönde değişebilmektedir. Merkezde yer alan çocuk açısından, ekosistemin bu farklı yüzleriyle, aile-akrabalarıyla birlikte uyum içerisinde çalıştığında sistemin dengede olduğu, çocuğun normal gelişimini sürdürdüğü söylenebilir. Çocukla ekosistem arasında uyumun olmaması halinde ise çocuğun gelişimsel dönemleri ve sağlıklı gelişimi açısından çeşitli riskler söz konusu olabilmektedir (Yolcuoğlu, 2010: 76).

Ekolojik Sistem Yaklaşımında, çocuğun bütün yaşam alanının incelenmesi önemlidir, yani ilgiler sadece çocuk yerine, canlı ve cansız çevreden oluşan etkileşim sistemleri üzerinde yoğunlaşır. Çocuğun davranışı, problemin sadece bir parçasıdır. Buna bağlı olarak da, bozukluğun çocuk ile çocuğu çevreleyen çevre arasındaki etkileşimde, yani çocuğun sisteminde yattığına inanılır. Yukarıda anlatılan sitemin farklı bölümleri ile çocuk uyum içinde olduğunda, sistem dengededir demektir. Ve bunun sonucu olarak çocuğun normal olduğu söylenir. Bunun tam tersi olarak, çevre ve çocuk uyum içinde değilse, çocuğun davranışı normalden sapar ve belki de bunun sonucu olarak suça sürüklenir. Durum böyle olunca, sistemin dengede 
olmadığı, elemanların birbiriyle çatışma içinde olduğu söylenir. Bu çatışmalar uyumsuzluk noktalarıdır, yani çocuk ile ekosistemi arasında uyumun olmamasıdır (Davaslıgil, 1997: 69).

Yukarıdaki tanım bağlamında çocukla yürütülen çalışmada, Danış’ın (2006) Butler'den (Butler, 1996: 48) aktardığı, davranış bilimi uygulayıcıları, mesleki ilişkinin başlangıcında, danışan bireyi (çocuğu), ailesini, komşuluk çevresini ve içinde yaşadığı toplumu analiz etmelidir (Danış, 2006: 52) ve Doğan'ın ifade ettiği, ekolojik yaklaşımda yer alan bu sistemler arasındaki tutarlılık ne kadar fazla ise, bu durumun çocuğun gelişimi üzerindeki etkisi de o kadar olumlu olacaktır yaklaşımından hareket edilmelidir. (Doğan, 2010: 157). Ve hareket noktası buradan alındığı için, yapılacak mesleki çalışmanın başlangıç noktası da burası olmalı ve çocuk ile sahip olduğu sistemlerin tutarlılık içine alınması yoluna gidilmelidir.

\section{OLGU SUNUMU}

Hakkında ilgili Mahkemece Danışmanlık Tedbiri kararı verilen çocuk T.Y ve ailesi ile Müdürlüğümüz Hizmet Binası ve ailenin ikamet adresinde görüşmeler gerçekleştirilmiştir. Yapılan ilk iki görüşme, çocuğun, ailesinin ve çevresinin tanınması için kullanılmış, aynı zamanda yapılacak olan görüşmelerin çerçevesi kişilere anlatılmış ve Danışmanlık Tedbirinin ne olduğu ve kişilerin sorumluluklarının ne olacağından söz edilmiştir. T.Y 16 yaşında, ortaöğretime giden bir erkek çocuğudur. Ders başarı düzeyi düşük ve devamsızlık yapma eğilimi olan bir öğrencidir. Öğrenim gördüğü ortaöğretim kurumu il merkezinde bulunmaktadır ve taşımalı yöntemle okula gidip gelmektedir. Çok fazla arkadaşının olmadığı, genelde ya birkaç arkadaşı ile ya da tek başına vakit geçirdiği öğrenilmiştir. Bunun yanında içe dönük bir kişilik yapısı olduğu anlaşılmıştır. Zaman zaman babası tarafından fiziksel şiddete maruz kalmakta olduğu da öğrenilmiștir. Birkaç arkadaşı ile bir bakkal dükkanından hırsızlık yapmak suçlamasıyla çıkartıldıkları mahkemece kendisine Danıșmanlık Tedbiri kararı verilmiștir. Baba 40 yaşında sürekli bir işi bulunmayan, iş buldukça inşaatlarda çalışan vasıfsız biridir. Daha önce karıştığı bir kavga nedeniyle kısa süreli cezaevinde kaldığını bilgisi alınmıştır. Anne ise 36 yaşında ev hanımıdır. Bunun dışında ailenin bir de 19 yaşında bir erkek çocuğu bulunmaktadır. Bu çocuk liseyi bitirememiş ve şuan, aynı babası gibi bulduğu takdirde günlük geçici işlerde çalışmaktadır. Aile ilimiz merkez köylerinden birinde ikamet etmektedir. Ev, tek katlı, bakımsız, iki oda bir salondan oluşan, kömür sobası ile 1sıtılan, duvarları sıvalı, bazı odalarında pencere olmayan, çatısından yağmur suyu akan, rutubetli betonarme bir yapıdır. Bunun yanında kömür sobasının yanmadığı ve evin soğuk olduğu görülmüştür. Bu ev T.Y'ın babasının babası tarafından aileye miras kalmıştır. Evde temel ihtiyaçları karşılayacak düzeyde eşya bulunmamaktadır. Ailenin sahip olduğu tek beyaz eşya bir buzdolabıdır. Yaşadıkları köyde birkaç akrabaları bulunmasına karşın, iletişimleri kötüdür. Hatta hem diğer akrabaları hem de diğer köylüler ile iletişim çatışmaları yaşamaktadırlar. Bununla beraber aile içi iletişimin seviyesi de çok düşük düzeydedir. Ailenin birlikte yaptığı herhangi bir etkinlik bulunmamakla birlikte, ne annenin ne de babanın çocuklarının takiplerini yapmadığı, kendi hallerine bıraktıkları görülmektedir. Buna karşın aileden çocukları hakkında olumsuz cümleler duyulmamış, aksine çocuklarını sevdikleri ve onların gelecekte iyi bir hayatları olmasını istedikleri bilgisi alınmıştır. Anne bir tam gününü evin içinde geçirmektedir. Baba ve büyük çocuk ise genelde dişarda vakit geçirerek iş aramaktadır. Bunun dışında büyük çocuğun kardeşi T.Y ile iletişimi de kaliteli değildir. Aralarında ciddi iletişim sorunları olmasa da, büyük çocuğun T.Y'ye abilik de yapmadığı anlaşılmıştır. T.Y ise okuldan arta kalan zamanlarında ya da okula gitmediği günlerde vaktini internet kafelerde çevirim içi oyun oynayarak ya da sosyal medyada aktif olarak geçirmektedir. T.Y bilgisayar kullanmayı çok sevdiğini ifade etmiştir.

Bunun dışında aile ile yapılan görüşmede, ailede herhangi bir sağlık sorunu olan kimse bulunmadığ öğrenilmiştir.

Alınan bu bilgilerden sonra, ailenin tüm üyeleri ile birlikte bir görüşme daha yapılmış ve ailenin ihtiyacı olan hizmetler belirlenmiştir. Bundan sonra hem aile içerisindeki ilişkilerin değerlendirilmesi yapılmış hem de ailenin içerisinde bulunduğu sistemler ile ilişkilerinin ve sistemlerin kendi aralarındaki ilişkilerin değerlendirilmesi amacıyla ekolojik haritası çıkartılmıştır. Son olarak yapılan görüşmelerin temel noktasına T.Y'nin yapmış olduğu "suç eylemi”" konulmamış, ailenin genel olarak güçlendirilmesi amaçlanmıştır.

Öncelikle ailenin ekolojik haritasının çıkartılması amaçlanmıştır. Bu nedenle, aile sistemi, bireylerin sistemi, okul sistemi gibi sistemlerin tanımları belirlenmiştir. Bundan sonrasında ise ailenin ihtiyaç duyduğu hizmetler üzerinden bu sistemlerin güçlendirilmesi planlanmıştır.

- T.Y'nin öğrenim gördüğü okul ile görüşme yapılması planlanarak, okul yönetiminden ve rehber ögretmenden destek istenmesi amaçlanmıştır. Ayrıca okula devamının sağlanması ve bu konuda 
motivasyonunun arttırılması için, T.Y ile geleceğinin nasıl olmasını istediği üzerinde görüşme gerçekleştirilerek farkındalık çalışmaları yapılacaktır. Bunun dışında ilgili Mahkemeden Eğitim Tedbiri de talep edilerek T.Y'nin okula devamı sağlanacaktır. Tam bu noktada aileye de çocuklarının okul takiplerini yapmalarının önemi noktasında görüşmeler gerçekleştirilecektir. Bu sayede okul yönetimi ve öğretmenler ile ailenin iletişimi de geliştirilmiş olacaktır.

- Ailenin ekonomik olarak düşük düzeyde olduğu görüldüğünden Aile ve Sosyal Politikalar İl Müdürlüğünce, okuyan çocuk T.Y için Sosyo - Ekonomik Destek (SED) verilmesi planlanmıştır.

- Ayrıca evin temel ihtiyaçlarının karşılanması noktasında Sosyal Yardımlaşma Dayanışma Vakfı (SYDV) ile iletişime geçilecek ve bu eksikliklerin giderilmesi sağlanacaktır.

- Burada önemli olduğu düşünülen bir diğer husus, ailenin yaşadığı çevredir. Aile burada yaşayan diğer insanlarla nitelikli iletişim kuramamaktadır. Ayrıca ailenin yaşadığı evin de insan onuruna yakışır bir yer olmadığı görüldüğünden, ailenin il merkezinde düşük kira ödeyecekleri bir eve taşınması için SYDV ile koordineli çalışacak, Vakıftan kullanılan kaynaklar ile ailenin taşınması sağlanacaktır. Bu sayede il merkezinin iş ve eğitim imkanları da daha etkili kullanılmış olacaktır. Ayrıca, aile, diğer insanlarla hiçbir iletişimi olmadığı bir yerden taşınarak hayatlarında yeni bir sayfa açmış olacaktır. Tam bu noktada aile ile yeni çevrelerine uyumları konusunda da çalışmalar yapılacaktır.

- Anne ve babanın çocuklarına olan yaklaşımı önemli bir sistem sorunu olarak değerlendirilmiş ve bu noktada çalışmalar planlanmıştır. Anne ve babaya ergenlik dönemi ve bu dönemde bulunan çocuklara yaklaşım konusunda eğitim verilecektir. Bu eğitim aynı zamanda aile içi iletişimi de kapsayacak ve nitelikli iletişim becerileri üzerine de çalışmalar yapılacaktır. Bunun dışında öfke kontrolü önemli bir konudur ve bu konuda da aileye bilgilendirmeler yapılacaktır.

- Bunun dışında başta T.Y olmak üzere baba ve diğer çocuğa kanunlar hakkında açıklama yapılacak, kanunlarda suç olarak belirtilen hususlar anlatılacaktır. Tam da bu bağlamda kanunların suç olarak tanımladığı eylemlerde bulunmanın kişilere neler kaybettirebileceği ve bu kişilerin geleceklerini nasıl etkileyeceği noktasında çalışmalar yapılarak ailenin erkek üyelerinin farkındalıklarının yükseltilmesi sağlanacaktır.

- Baba henüz 40 yaşındadır ve herhangi bir sağlık sorunu da yoktur. Bu nedenle babanın çalışma hayatına atılması gerekmektedir. Bu konuda baba ile motivasyon üzerine çalışmalar yapılacaktır. Ailenin diğer çocuğu henüz genç yaştadır ve o da işsizdir. Bu nedenle bu çocuk ile de motivasyon çalışması yapılacaktır. Öncelikle eğitimini tamamlaması üzerinde görüşmeler gerçekleştirilecek ve lise diploması alması noktasında cesaretlendirilecektir. Bunun dışında, kendisinin de istemesi ve kişiliğine de uygun olduğunu düşündüğü için bir özel güvenlik kursuna kayıt olması için de kendisine rehberlik yapılacaktır. Annenin ise, bakacak küçük bir çocuğu olmadığı için, çalışmasına engel bir durumu bulunmamaktadır. Bu noktada anneye de Halk Eğitimi Merkezi ya da Belediyelerin açacağı meslek kurslarına kayıt yaptırması için rehberlik yapılacak hatta bu konuda kendisine yardım edilecektir.

- T.Y, okuldan arta kalan zamanlarında Halk Eğitimi Merkezinin açacağı Bilgisayar, Web Tasarımı, Ön Muhasebe, Ofis Programı kullanımı gibi kurslara katılması için teşvik edilecektir. T.Y bilgisayar kullanmayı, bilgisayar ile vakit geçirmeyi sevdiğini belirtmiştir. Bu sayede hem başka mesleki yetenekler kazanmış olacak hem de okul sonrası zamanını daha nitelikli kullanmış olacaktır. Ayrıca bu sayede farklı insanlar tanıyacak ve kendini hem yenileyecek hem de geliştirmiş olacaktır.

- Aile içi iletişimin nitelikli olmaması ve T.Y'nin ailede zaman zaman baba şiddetine de maruz kalması nedeniyle olacak ki içine kapanık bir yapısı vardır. Bu noktada diğer disiplinlerden de yardım alınmasının önemli olduğu düşünüldüğünden, mahkemeden Sağlık Tedbiri talep edilecek ve T.Y'nin psikiyatrik tedavi görmesi de sağlanacaktır.

-Son olarak aileye Danışmanlık Tedbiri kapsamında yapılacak çalışmaların bitiminden sonra, ihtiyaç duydukları konularda kendilerine rehberlik yapılabileceği de anlatılacaktır. Bunun dışında hangi Devlet Kurumunun hangi görevi yaptığı da aileye anlatılıp ve bu konuda da bilgi sahibi olmaları sağlanacaktır. 


\section{SONUC VE TARTISSMA}

Yapılan mesleki çalışmada aile üyeleri ile 16 görüşme gerçekleştirilmiştir. Bunun dışında okul idaresi ve öğretmenleri, mesleki eğitim veren kurs yetkilileri, SYDV personeli ile de görüşmeler gerçekleştirilmiştir. Çalışma toplam 4 ay sürmüştür.

Yapılan tüm mesleki çalışmalar sonunda başta T.Y olmak üzere aile bireylerinde olumlu gelişmeler görülmüştür. Aile il merkezinde bulunan bir eve kiracı olarak geçmiştir. Mesleki çalışmaların etkisi, il merkezinde de yaşamanın vermiş olduğu imkanlar ile, baba iş aramak ve çalışmak için motive olmuş ve bunun sonucunda, bir fabrikada bekçi olarak çalışmaya başlamıştır. Aldığı maaş ile evin kirasını karşılayabilmiş ve evin diğer ihtiyaçları için de kaynak sağlamıştır. Diğer çocuk ise Açık Liseye kayıt olmuştur. Bunun dışında şehirlerarası yolcu taşımacılığı yapan bir otobüs firmasında host olarak göreve başlamıştır. O da aileye ekonomik olarak katkı sağlamıştır. Anne ise çocuk bakımı, yaşlı bakımı ve aşçılık gibi mesleki kurslara kayıt olmuştur. Henüz bir işi yoktur. Fakat ASP İl Müdürlüğünden kısa süreli SED yardımı almıştır. T.Y ise okuldan arta kalan zamanlarında web tasarımı kursuna gitmeye başlamıştır. Aile şuan için ekonomik sıkıntılarından kurtulmuş görülmektedir.

Ailenin ekonomik düzeyinin yükselmesinin, aile üyelerinin kendilerini daha işe yarar hissetmelerinin ve kendileri ile yapılan aile içi iletişim, ergenlik dönemi özellikleri, öfke kontrolü gibi mesleki çalışmaların da katkısı ile, aile de pozitif bir hava görülmüsşür. Aile üyeleri birlikte vakit geçirmeye çaba göstermiş, hafta sonlarını ekonomik imkanları ölçüsünde sosyal faaliyetler ile değerlendirmiş, birbirlerine saygı göstermiş̧ir. Aile içi iletişim, tartışmacı değil, cesaretlendirici olmuştur, düşmanca, kötüleyici, cezalandırıcı bir yaklaşım ebeveynler tarafından terk edilmiş ve daha olumlu bir iletişim modeli tercih edilmeye başlanmıştır.

T.Y ise; bu çalışmalar ve sonuçlarının olumlu olmasından dolayı son derece mutlu olduğunu, özgüveninin arttığını, okula devam ediyor olmanın ve ders başarı düzeyinin yükselmesinin psikolojisinde belirgin bir düzelme yarattı̆̆ını ve artık geleceğini planlayarak ve ona göre adımlar atarak yaşayacağını ifade etmiştir. T.Y'nin bu söyledikleri ile örtüşür şekilde, çevresi ve ailesi ile daha yapıcı ve daha samimi iletişim tarzı benimsediği de görülmüştür.

Sonuç olarak, aile ile birlikte planlanan neredeyse tüm hedeflere varıldığı görülmüştür. Çerçevesi aile ile birlikte çizilen bu mesleki çalışma Davaslıgil'in (1997: 74) makalesinde belirttiği gibi, önlemler eldeki ekosistemin tüm elemanları üzerinde yoğunlaşmış, dikkatler sadece çocuğa çevrilmemiş ve bu fikirden hareketle çalışma planı yapılandırılmıştır. Aynı şekilde Özbesler ve Bulut'un (2013: 98) belirttiği gibi, Genel Sistemler Kuramının birleştirici bir kuram olduğu kabul edildiğinden ve nesneleri ve insanları ayrı ayrı değil, ilişkileri içinde incelemek gerektiği bakış açısıyla hareket edilmiş ve suça sürüklenen çocuk üzerinde yoğunlaşılmamış, çocuk ilişkileriyle birlikte ele alınmıştır. Ekolojik Sistem Yaklaşımında davranış ile o davranışın ortaya çıktığı ortam arasındaki ilişkiye odaklanıldığından, sistemi oluşturan ilişkiler ağının bir noktasında meydana gelen değişimin, ağ boyunca yayılarak diğer bütün noktaları da etkileyeceği görüşünde olduğu gibi, bu çalışmada da, her bir sistemin birbirini nasıl etkilediği görülmüsştür. Danış'ın (2006: 46), çevresel etkenlerin sorunlar üzerindeki etkisinin önemi anlaşılarak, sorunların nedenlerinin sadece bireylerde ve içsel yaşantılarda aranmasının aynı zamanda sorunu olan bireylerin suçlanmasını da beraberinde getireceği inancı giderek önem kazanmıştır tespitinden yola çıkılmış ve aileye ve çocuğa bu şekilde yaklaşılmıştır. Bu nedenle çocuk bir suçlu olarak değil, suça sürüklenen olarak görülmüş ve kendisine bu şekilde yaklaşılmıştır. Bu da çocuğun motivasyonunu arttırmış ve mesleki çalışmanın başarısının baş̧langıcı olmuştur. Çalışma boyunca yapılması planlanan tüm etkinlikler hep ekolojik sistem yaklaşımı çerçevesinde gerçekleşmiştir. Bu bakış açısı ile ailenin içinde bulunduğu tüm sistemlere ailenin kendisinin dokunması amaçlanmış ve bu konuda sadece yol gösterici, motive edici bir rol oynanmıştır.

Sonuç olarak bakıldığında, Ekolojik Sistem Yaklaşımının, bu alanda çalışan meslek elemanının elini kuvvetlendirdiği ve mesleki başarının önemli bir anahtarı olduğu görülmüştür. 


\section{KAYNAKÇA}

Arıkan, Ç. (1986). Psiko-sosyal yönleriyle sapma, Hacettepe Üniversitesi Sosyal Hizmetler Yüksekokulu Dergisi, 4: 2-3.

Çelik, C. (2007). Niklas Luhmann'da Sosyal Sistem Olarak Toplum ve Modern Toplumun Karmaşıklığ1 Sorunu, Bilimname XII, 2007/1: 51-74.

Çocuk Koruma Kanunu (2005). T. C. Resmi Gazete, 25876, 15.07.2005.

Danış, Z. ( 2006). Davranış Bilimlerinde Ekolojik Sistem Yaklaşımı, Aile ve Toplum, 8 (3): $45-53$.

Danış, Z. ve Şahbikan, İ. (2014). Suça Sürüklenmiş Çocukların Yeniden Toplumsallaşma Sürecinde ve İnsan Hakları Bağlamında Sosyal Hizmet Yaklaşımlarının Yeri ve Önemi, Tarih Okulu Dergisi (TOD), 7 (18): 627-651.

Danışmanlık Tedbir Kararlarının Uygulama Usul ve Esasları Hakkında Tebliğ (2008). T.C. Resmi Gazete, $27035,25.10 .2008$.

Davaslıgil, Ü. ( 1997 ). Ekolojik Yaklaşımın Psikoloji ve Eğitime Uygulanması, Eğitim ve Bilim Dergisi, 21 (103): 66-79

Doğan, A. (2010). Ekolojik Sistemler Kuramı Çerçevesinde Akran Zorbalığının İncelenmesi, Çocuk ve Gençlik Ruh Sağlığı Dergisi, 17 (3), 149-162.

Duyan, V. (2013). Sosyal Hizmet Kuramları ve Yaklaşımları. Erzurum: Atatürk Üniversitesi Açı Öğretim Fakültesi Yayınları.

Giddens, A. (2000). Sosyoloji (H. Özel ve C. Güzel Çev.). Ankara: Ayraç Yayınevi.

Gökten E. (2011) 2009-2011 yılları arasında bir devlet hastanesinde Çocuk Psikiyatrisi Polikliniği'ne yönlendirilen adli olgular, Çocuk ve Gençlik Ruh Sağlığı Dergisi, 18(2): 105-116.

Kılıçarslan, F. (2006). Çocuk ve Aile Sorunlarının Terapi ile Tedavisi. Ankara: Nobel Yayın Dağıtım.

Kızılcelik S. Erjem Y. (1996). Açıklamalı Sosyoloji Sözlüğü. İzmir: Saray Kitabevleri

Kozaman, S. ve Şengezer, B. (2013). Sosyo- Ekolojik Sistem Yaklaşımı Bağlamında Türkiye'de Çevresel Değişimler ve Sosyo Ekonomik Yapı İlişkisi, Megaron, 8(3):179-189.

Köknel, Ö. (1987) İnsanı Anlamak. İstanbul: Altın Kitaplar.

Öter, A. (2005). Çocuk Suçluluğunun Toplumsal Nedenleri (Antalya Örneği) (Yüksek Lisans Tezi). Isparta: Süleyman Demirel Üniversitesi Sosyal Bilimler Enstitüsü.

Özbesler, C. ve Bulut, I. (2013). Sosyal Hizmette Genelci Yaklaşım ve Ekolojik Perspektif. Sosyal Politika ve Kamu Yönetimi Bileșenleriyle Sosyal Hizmet Temelleri ve Uygulama Alanları, Akademi, 2013: 97-107

Salk, L. (1998) Çocuğun Duygusal Sorunları (E. Onur Çev.). İstanbul: Remzi Kitapevi.

Sankır, H. (2014). Gençlerin Sapmış ve Suçlu Davranışlara Yönelmelerinde Benlik Saygısının Etkisi: Lise 11. Sınıf Örneği, Turkish Studies, 9/2: 1311-1333.

Uşaklı, H. (2013). Eşinden Ayrılmış Annelerin Görüşü Açısından Çocuklarının Sorunu, Karabük Üniversitesi Sosyal Bilimler Enstitüsü Dergisi, 3(2) 195-208.

Yavuzer, H. (2006). Çocuk ve Suç. İstanbul: Remzi Kitabevi. 
Yavuzer, H. (2011). Gençleri Anlamak. İstanbul: Remzi Kitapevi.

Yolcuoğlu, İ. Galip (2010). Çocukların İhmal-İstismara Uğramasında Aile ve Çocuklara Yönelik Risk Faktörleri ve Sosyal Hizmet Müdahalesi, Toplum ve Sosyal Hizmet 21(1): 73-83.

Yörükoğlu, A. (1978). Çocuk Ruh Sağlığı. Ankara: T.C. İş Bankası Kültür Yayınları.

Yücel, T. Mustafa (1993). "1980-1992 Yılları Arasında Türkiye'de Çocuk Suçluluğu”, Adliye ve Çocuk Suçluluğu Sempozyumunda Sunulan Bildiri, İstanbul: Marmara Üniversitesi Hukuk Fakültesi, Yayın no: 441: 155-177. 